\title{
Serpins in rice: protein sequence analysis, phylogeny and gene expression during development
}

\author{
Sheila E Francis ${ }^{1}$, Renan A Ersoy ${ }^{1}$, Joon-Woo Ahn ${ }^{1,4}$, Brian J Atwell ${ }^{2}$ and Thomas H Roberts ${ }^{1,3^{*}}$
}

\begin{abstract}
Background: Most members of the serpin family of proteins are potent, irreversible inhibitors of specific serine or cysteine proteinases. Inhibitory serpins are distinguished from members of other families of proteinase inhibitors by their metastable structure and unique suicide-substrate mechanism. Animal serpins exert control over a remarkable diversity of physiological processes including blood coagulation, fibrinolysis, innate immunity and aspects of development. Relatively little is known about the complement of serpin genes in plant genomes and the biological functions of plant serpins.

Results: A structurally refined amino-acid sequence alignment of the 14 full-length serpins encoded in the genome of the japonica rice Oryza sativa cv. Nipponbare (a monocot) showed a diversity of reactive-centre sequences (which largely determine inhibitory specificity) and a low degree of identity with those of serpins in Arabidopsis (a eudicot). A new convenient and functionally informative nomenclature for plant serpins in which the reactive-centre sequence is incorporated into the serpin name was developed and applied to the rice serpins. A phylogenetic analysis of the rice serpins provided evidence for two main clades and a number of relatively recent gene duplications. Transcriptional analysis showed vastly different levels of basal expression among eight selected rice serpin genes in callus tissue, during seedling development, among vegetative tissues of mature plants and throughout seed development. The gene OsSRP-LRS (Os03g41419), encoding a putative orthologue of Arabidopsis AtSerpin1 (At1g47710), was expressed ubiquitously and at high levels. The second most highly expressed serpin gene was OsSRP-PLP (Os11g11500), encoding a non-inhibitory serpin with a surprisingly well-conserved reactive-centre loop (RCL) sequence among putative orthologues in other grass species.

Conclusions: The diversity of reactive-centre sequences among the putatively inhibitory serpins of rice point to a range of target proteases with different proteolytic specificities. Large differences in basal expression levels of the eight selected rice serpin genes during development further suggest a range of functions in regulation and in plant defence for the corresponding proteins.
\end{abstract}

Keywords: Serpin, Protease inhibitor, Rice, Oryza sativa, Arabidopsis thaliana, Expression

\footnotetext{
* Correspondence: thomas.roberts@sydney.edu.au

'Department of Chemistry and Biomolecular Sciences, Macquarie University,

North Ryde, NSW 2109, Australia

${ }^{3}$ Department of Plant and Food Sciences, Faculty of Agriculture and

Environment, University of Sydney, Sydney, NSW 2006, Australia

Full list of author information is available at the end of the article
} 


\section{Background}

Serpins constitute one of more than 80 families of protease inhibitors in nature [1] but are the dominant family in animals [2]. Serpins have been shown to be involved in a remarkable diversity of physiological processes in humans and in distinct model animal systems [3]. Most animal serpins act biochemically as irreversible inhibitors of specific endogenous serine (less commonly cysteine) proteinases [2]. For example, the well-studied mammalian serpin, antithrombin (SERPINC1), is an inhibitor of several of the activated forms of blood coagulation factors including thrombin (Factor IIa) as well as other serine proteinases of the chymotrypsin family [4].

The nomenclature of the secondary structural elements of serpins (using human $\alpha_{1}$-antitrypsin as a model) was defined more than 20 years ago [5]. A typical serpin molecule is characterised by three $\beta$-sheets $(\mathrm{A}-\mathrm{C})$, eight to nine $\alpha$-helices $(\mathrm{A}-\mathrm{H})$ and a reactivecentre loop (RCL). The RCL displays an extended, exposed proteinase bait protruding from the body of the serpin scaffold and is one of several features critical for the function of inhibitory serpins [6]. The first X-ray crystal structure of a plant serpin-that of Arabidopsis thaliana AtSerpin1 (locus At1g47710) in the native, stressed conformation-was obtained recently and shown to be consistent with the description above but to also display plant-specific features [7].

Serpins inactivate their target proteinases using a unique mechanism involving large conformational change and a loss of structural metastability of the serpin to form a kinetically stable, covalent complex with the target enzyme [8]. In the native, stressed conformation of the serpin, the RCL presents a bait sequence to the proteinase [9]. (Note: RCL residues $N$-terminal from the protease cleavage site are defined as P1, P2, P3, etc., while those on the $C$-terminal side are termed $\mathrm{P}^{\prime}, \mathrm{P} 2^{\prime}$, $\mathrm{P}^{\prime}$, etc. [10]). Upon cleavage of the RCL at the P1-P1' bond of the reactive centre by the proteinase, the RCL inserts as an extra strand into the main $\beta$-sheet of the serpin molecule and the covalently attached proteinase $[11]$ is flung to the opposite end of the serpin $[12,13]$. The conformational change in the serpin from native to cleaved is known as the stressed-to-relaxed $(S \rightarrow R)$ transition [14]. The proteinase is crushed against the body of the serpin, thereby distorting the active site of the enzyme and preventing hydrolysis of the peptide bond between the active-site Ser (or Cys) of the proteinase and the P1 residue of the serpin $[13,15]$.

The inhibitory specificity of a serpin depends largely on the identity of residues in the reactive centre, particularly $\mathrm{P} 1$, although additional residues from $\mathrm{P} 6$ to $\mathrm{P} 3^{\prime}$ $[16,17]$ as well as exosite interactions [8] may influence the efficiency of proteinase inhibition. A minority of serpins have lost their inhibitory activity over the course of evolution [18] and have adapted to other roles. For example, the mammalian non-inhibitory serpins corticosteroid binding globulin (CBG; SERPINA6) and thyroxin-binding globulin (TBG; SERPINA7) bind steroid hormones in the blood and release these compounds at specific sites via a mechanism involving cleavage of the RCL $[19,20]$.

While dozens of intra- and extracellular animal serpins have been functionally characterised, relatively little is known about the functions of serpins in plants [21-23] nor indeed in unicellular eukaryotes [24-26] and prokaryotes [25,27-29]. Within the Viridiplantae, serpin genes have been identified in unicellular green algae, bryophytes, gymnosperms and flowering plants [22]. Testing via in vitro inhibition assays has shown that nearly all plant serpins studied are potent inhibitors of specific mammalian serine proteinases [30-36]. AtSerpin1 from Arabidopsis has been shown to inhibit Metacaspase 9 (AtMC9), an endogenous cysteine proteinase, in vitro [37]. More recently, the major in vivo target proteinase for AtSerpin1 was identified as the papain-like cysteine proteinase RESPONSIVE TO DESICCATION-21 (RD21) [7], an enzyme that also has transpeptidase activity [38]. Two other Arabidopsis serpins, AtSRP2 (ArathZ2; At2g14540) and AtSRP3 (ArathZ1; At1g64030), are associated with plant responses to alkylating DNA damage [39]. Serpins found at high concentrations in seeds (up to $4 \%$ total protein in wheat grain [34]) are assumed to provide direct defence against exogenous proteinases from insects and other organisms that attack the endosperm and other seed tissues $[21,22,34]$.

The fully sequenced genome of japonica rice (Oryza sativa cv. Nipponbare) has been analysed to identify all serpin genes using PSI-BLAST searching [21,22]. A total of 14 genes encoding full-length serpins (340-440 amino-acid residues) were identified, eight of which were associated with evidence for expression based on publicly available ESTs, microarrays and proteomics data. The RCL sequences of these serpins were aligned to determine whether each sequence was likely to represent an inhibitory or a non-inhibitory serpin [22]. One of the rice serpins, here named OsSRP-PLP (Os11g11500), featured an RCL sequence that strongly suggested it was a non-inhibitory serpin, while two of the other serpins were less confidently predicted as being non-inhibitory. For the eleven putatively inhibitory serpins, the reactive-centre $\mathrm{P} 2-\mathrm{P} 1^{\prime}$ sequence was different in each case, with considerable diversity associated with the critical P1 residue. Indeed, positively charged (Arg and Lys), small uncharged (Ala, Gly, Ser) and hydrophobic (Leu, Met) residues were identified at this position [22].

The aims of this study were to create a new nomenclature for the rice serpins, which could be extended to 
other species, and to describe the complement of rice serpin proteins, examine their phylogeny and measure the basal expression levels of their genes during plant development. We: (i) produced a phylogenetic analysis of the 14 full-length serpins in O. sativa cv. Nipponbare based on a carefully curated alignment of protein sequences (derived from revised gene models for several of the serpins); (ii) showed the extent to which genomic PCR using primer sets designed for O. sativa cv. Nipponbare could amplify serpin genes in other varieties of $O$. sativa and in wild species of Oryza; (iii) determined the basal expression pattern of eight selected rice serpin genes in callus, seedlings during development, organs of mature plants and in developing seeds, and (iv) compared the rice serpins to those in Arabidopsis to identify putative orthologues.

\section{Methods}

Amino-acid sequence alignment and phylogenetic analysis

Sequences were aligned using ClustalX [40] and edited by hand to ensure alignment of the residues as constrained by the length of the RCL [41]. The alignment was augmented with the amino-acid sequence of AtSerpin1 along with corresponding secondary structure assignments based on the X-ray crystal structure of the native conformation [7]. For construction of the phylogenetic tree, an msf file was generated and imported into PAUP v4.0b10 [42]. All sites in the alignment with gaps in any sequence were excluded and the remaining sites processed using parsimony (default settings in PAUP). A tree was constructed with 1000 bootstrap trials. The resulting .phb file was imported into TreeView X v0.5.0 [43] and a rectangular cladogram constructed.

\section{Plant growth conditions \\ Origin and sterilisation of rice seeds and growth of seedlings on solid media}

Oryza sativa cv. Nipponbare seeds were obtained from Dr. Alexander Johnson, University of Adelaide, Australia. Other O. sativa varieties were obtained from SunRice (Leeton, NSW). The O. australiensis seeds were obtained via the Australian Plant Genetic Resource Information Service (ATCGRC \#122; http://www2.dpi.qld.gov.au/extra/ asp/AusPGRIS/) and the O. meridionalis seeds were collected from Cape York, Queensland $\left(15^{\circ} 41^{\prime} \mathrm{S}\right.$ and $\left.145^{\circ} 2^{\prime} \mathrm{E}\right)$.

Seeds were dehulled and washed with $0.5 \mathrm{mM} \mathrm{CaCl}_{2}$ for $30 \mathrm{~min}$ on a shaker at low speed. $\mathrm{The}^{\mathrm{CaCl}} \mathrm{C}_{2}$ solution was discarded and the seeds were incubated in $70 \%$ ethanol for $30 \mathrm{~s}$. After three washes with sterile distilled water, the seeds were placed in $10 \%$ commercial bleach for $3 \mathrm{~min}$ followed by a single wash in water and incubation in $\mathrm{HgCl}_{2}(1000 \mathrm{ppm})$ solution for $3 \mathrm{~min}$. Finally the seeds were rinsed in sterile distilled water $(5 \times 1 \mathrm{~min})$.
Sterile cylindrical Perspex jars $(15.5 \mathrm{~cm}$ high $\times 6.8 \mathrm{~cm}$ diameter) containing sterile medium were prepared by adding $\sim 50 \mathrm{ml} 1 \times$ Murashige and Skoog (MS) salt medium and $0.8 \%$ agar into each jar, placing nonabsorbent cotton wool in the air vent in the top of each jar and autoclaving the jars at 121 psi for $20 \mathrm{~min}$. The sterilised seeds were placed on top of the media in the jars (in a laminar flow cabinet), which were then kept in the dark for $5 \mathrm{~d}$. Since the seeds germinated $\sim 3 \mathrm{~d}$ after imbibition, seedlings collected immediately after the 5-d imbibition are referred to as 2-d-old seedlings. The remaining of the seedlings were transferred into sterile jars containing MS medium. The jars were placed in a growth chamber (Thermoline) with a cycle of $16 \mathrm{~h}$ at $28^{\circ} \mathrm{C}$ in the light and $8 \mathrm{~h}$ at $15^{\circ} \mathrm{C}$ in the dark. The light intensity was $215 \mu$ moles $\mathrm{m}^{-2} \mathrm{~s}^{-1}$ provided by GE Polylux XL fluorescent tubes (model F38U/840 CVG).

\section{Growth of plants in soil and isolation of mature plant tissues and developing seeds}

Rice seeds were dehulled, soaked in $0.5 \mathrm{mM} \mathrm{CaCl}_{2}$ for $30 \mathrm{~min}$ and sown in soil (equal parts of a fine-textured krasnozem from Robertson, NSW, a silty clay-loam from Bungendore, near Canberra, ACT, and general potting mix (Australian Native Landscapes)) in pots. The pots were placed in trays of water in a temperaturecontrolled glasshouse, $28^{\circ} \mathrm{C}$ for $\sim 16 \mathrm{~h}$ (day) and $15^{\circ} \mathrm{C}$ for $\sim 8 \mathrm{~h}$ (night). Plants were grown for $6-8$ weeks from germination. Samples of leaf, stem, root and root tip (cut $\sim 2 \mathrm{~mm}$ from the end of the roots) were collected, frozen in liquid nitrogen and stored at $-80^{\circ} \mathrm{C}$. Developing seeds were collected at $5,10,15,20,30$ and $40 \mathrm{~d}$ post-anthesis, frozen in liquid nitrogen and stored at $-80^{\circ} \mathrm{C}$.

\section{Isolation of DNA and genomic PCR}

Seeds from the $O$. sativa cultivars and wild Australian relatives were sown in soil as described above. After 6-8 weeks, leaves from each variety were harvested, frozen in liquid nitrogen and ground using a pre-chilled mortar and pestle. Total genomic DNA was extracted using the DNeasy ${ }^{\circ}$ Plant Mini kit (Qiagen) according to the manufacturer's instructions. The PCR cycle and primers used were the same as described for the semi-quantitative RT-PCR.

\section{Isolation of RNA and semi-quantitative RT-PCR}

Total RNA was extracted from $100 \mathrm{mg}$ plant tissue using an RNeasy Plant Mini kit (Qiagen) according to the manufacturer's instructions. For RT-PCR, total RNA $(10 \mu \mathrm{g})$ was treated with DNA-free ${ }^{\mathrm{TM}}$ (1 unit of RNase-free DNase; Ambion). The first-strand cDNAs were synthesised using $5 \mu \mathrm{g}$ DNase-treated total RNA with oligo(dT) $(50 \mu \mathrm{M}), 200 \mathrm{U}$ Superscript III reverse transcriptase (Invitrogen), $10 \mathrm{mM}$ dithiothreitol (DTT), $500 \mu \mathrm{M}$ of each 
Table 1 Primers used for semi-quantitative RT-PCR

\begin{tabular}{|c|c|c|}
\hline Primer & Sequence & $\begin{array}{l}\text { Amplicon } \\
\text { size (bp) }\end{array}$ \\
\hline OsSRP-QKG fwd & 5'-TGCCCCGAGCCGCATTCTAC-3' & 359 \\
\hline rvs & $5^{\prime}$-TTGCATCATAACCACGGCGG-3' & \\
\hline OSSRP-LGC fwd & 5'-GACACCGGCCGCCTCTTCTC-3' & 383 \\
\hline rvs & $5^{\prime}$-GCGCAGCCAAGGGTCATGAC-3' & \\
\hline OsSRP-LRS fwd & 5'-AAGCTTCCATACCAGCAAGG-3' & 395 \\
\hline rvs & 5'-GGAGCTGACCTAAGTGTGATC-3' & \\
\hline OsSRP-FRS fwd & 5'-GCTTATGGCTTGACCACAAG-3' & 451 \\
\hline rvs & 5'-CACTGCCTTCCATCACGTAG-3' & \\
\hline OsSRP-PTY fwd & $5^{\prime}$-ACGACGGCCAGGTCCACTTC-3' & 398 \\
\hline rvs & 5'-GCTATAGGTCGGGCTGCAAC-3' & \\
\hline OsSRP-PLP fwd & 5'-AGCAAGGAAAGAATGAAAGG-3' & 362 \\
\hline rvs & 5'-CAAGCCCATTGATACTGAAG-3' & \\
\hline OsSRP-FAS fwd & 5'-GCTTGTGTGAGCGCGAGGAC-3' & 399 \\
\hline rvs & 5'-GAAGGTAAGACAAACCGCGG-3' & \\
\hline OsSRP-FLC fwd & 5'-GATGGTGGTGACATCACTCC-3' & 423 \\
\hline rvs & 5'-CAAGAACTTCATCGTGCAGG-3' & \\
\hline Actin fwd & 5'-TCCATCTTGGCATCTCTCAG-3' & 418 \\
\hline rvs & $5^{\prime}$-GTACCCGCATCAGGCATCTG-3' & \\
\hline
\end{tabular}

BLASTN searches against the rice genome using the primers as query sequences were performed to check for the possibility of non-specific hybridisation. fwd = forward; rvs = reverse.

dNTP and 20 U RNase inhibitor. For PCR amplification, the following components were combined in a $0.2-\mathrm{ml}$ tube: cDNA template, $1 \times$ reaction buffer (Thermo Scientific), $2.0 \mathrm{mM} \mathrm{MgCl}$ (Thermo Scientific), $0.2 \mathrm{mM}$ dNTPs (Qiagen), 0.8 M betaine (Sigma), 0.8 U Taq polymerase (Red Hot Taq from Integrated Sciences) and $10 \mathrm{pmol}$ of each primer (forward and reverse primers as listed in Table 1). Sterile Milli-Q water was added to give a final volume of $20 \mu \mathrm{l}$. The PCR cycle was $94^{\circ} \mathrm{C}$ for $5 \mathrm{~min}, 35$ cycles of $94^{\circ} \mathrm{C}$ for $30 \mathrm{~s}, 55^{\circ} \mathrm{C}$ for $30 \mathrm{~s}$ and $72^{\circ} \mathrm{C}$ for $2 \mathrm{~min}$ and a final extension step of $72^{\circ} \mathrm{C}$ for 5 min with a Px2 thermal cycler (Thermo Electron Corporation).

Primers were obtained from Sigma. Primer pairs and their expected amplicon sizes for semi-quantitative RTPCR and genomic PCR experiments are shown in Table 1. The regions chosen for the forward and reverse primers corresponded to $\sim 400 \mathrm{bp}$ upstream from the DNA sequences encoding the hypervariable RCL region and to the hypervariable RCL region itself, respectively. The primer pairs were first tested using genomic PCR. Single PCR products of the expected sizes were obtained for each of the eight primer pairs and no bands were present in any of the minus-template controls (results not shown). Amplicon sequencing using a 3130X/Genetic Analyzer (Applied Biosystems) followed by BLASTN searching against the "Genes in MSU Osal Rice
Pseudomolecules - Genomic" database using default parameters (including Expect threshold =10) at the MSU Rice Genome Annotation website (http://rice.plantbiology. msu.edu/) confirmed that all of the PCR products amplified corresponded to the expected genes (not to other serpin genes, serpin pseudogenes or unrelated genes; results not shown).

\section{Real-time RT-PCR}

For quantitative real-time RT-PCR, the QuantiTect SYBR ${ }^{\circ}$ Green PCR kit (Qiagen) was used with a LightCycler ${ }^{\circ}$ (Roche). As performed above for the semi-quantitative RT-PCR primers, real-time primers (Table 2) were tested by genomic PCR followed by BLASTN searching using the sequencing products as queries. All of the PCR products amplified corresponded to the expected genes (results not shown).

The samples were diluted to 50-125 $\mathrm{ng} \mathrm{\mu l}^{-1}$ and run as three technical replicates (triplicates). The CP (crossing-point) values were detected by the LightCycler ${ }^{\circ} \mathrm{Soft}-$ ware v.4.0. Expression profiles were compared with that of the housekeeping gene, Actin (Os03g50885). In some experiments a second housekeeping gene, GAPDH (Os04g40950) was also included.

To allow presentation of real-time RT-PCR data for poorly-expressed genes (e.g. OsSRP-PTY) and highlyexpressed genes (e.g. OsSRP-LRS) on single figures, the CP values from the LightCycler analysis were firstly transformed by assigning (arbitrarily) a CP value of 20.00 to a

Table 2 Primers used for real-time RT-PCR

\begin{tabular}{rll}
\hline \multicolumn{1}{l}{ Primer } & Sequence & $\begin{array}{l}\text { Amplicon } \\
\text { size (bp) }\end{array}$ \\
\hline OsSRP-QKG fwd & 5'-ACATGCGGAAGCTGGGCGTGA-3' & 167 \\
rvs & 5'-TTGCATCATAACCACGGCGGTG-3' & \\
OsSRP-LGC fwd & 5'-ACAAGACGAACGCGGCGGAGAC-3' & 133 \\
rvs & 5'-TGGTAGACGGCCGACACGACGA-3' & \\
OsSRP-LRS fwd & 5'-ACGCGGCAAGTACTGTCGGGC-3' & 228 \\
rvs & 5'-TGCAGCAGCAGCCTCAGTCCC-3' & \\
OsSRP-FRS fwd & 5'-GGCTGCGAAGCTGAACTCTGAAC-3' & 197 \\
rvs & 5'-TCTCTGGAGAACCCACCATCCCA-3' & \\
OsSR-PTY fwd & 5'-AGCGAGCAGGAAGTCTCCCCG-3' & 155 \\
OsSRP-PLP fwd & 5'-GGCGGCGTGTCACACTCACA-3' & \\
rvs & 5'-CCTCCGGGAAGCTGAATTCTCTG-3' & 220 \\
OsSRP-FAS fwd & 5'-TCACTGTCCAGAGACCTCCTCCC-3' & \\
rvs & 5'-CGCCGCCGATGCGAGGCGGACC-3' & 170 \\
OsSRP-FLC fwd & 5'-AAGATGGCAGTGGCGTCGTCCG-3' & 303 \\
rvs & 5'-CTTCATCGTGCAGGCCGTGG-3' & \\
\hline
\end{tabular}

BLASTN searches against the rice genome using the primers as query sequences were performed to check for the possibility of non-specific hybridisation. fwd $=$ forward; rvs = reverse.fwd = forward; rvs = reverse. 
relative transcript abundance of 100,000 units (expression value $=100,000 \times 2^{(20-x)}$, where $\mathrm{x}$ is the $C P$ value obtained for the gene analyzed) and then plotted on a $\log _{10}$ scale on the Y-axis. The CP value of 20.00 was convenient because the basal expression of Actin (the most highly expressed gene measured) corresponded to $\mathrm{CP} \sim 20$. To assist in interpreting the relative transcript abundance values plotted on the $\log _{10}$ scale, the values in each figure are also given in an integrated table immediately below each plot.

\section{Results}

\section{A new rice serpin nomenclature}

In a detailed review of plant serpins conducted previously, each of the 14 full-length serpins encoded in the O. sativa cv. Nipponbare genome was assigned a unique name, such as OrysaZ2a [22]. Since serpins from $\sim 60$ plant species were compared in the review, serpin names included a five-letter abbreviation for the Latin name (e.g. Orysa for Oryza sativa). The "Z" designation was derived from "Protein Z", the name given to barley grain serpins [44] before the word "serpin" was coined [45]. Numbers in the names were based on a combination of degree of overall identity and of RCL length and sequence to previously named plant serpins. Where no match to a previously named serpin was found, the number of that serpin was avoided (thus, for example, none of the rice serpins was named OrysaZ7 because none had sufficient general similarity as described above to barley serpin Z7). Recently, one of the rice serpins was named OsSerpin [46] but a more appropriate name may have been OsSerpin1 because this particular serpin is the reactive-centre match and putative orthologue of AtSerpin1, as named earlier [37].

Here we created a new, alternative nomenclature for rice serpins by (i) shortening the first part of the name to "Os" for Oryza sativa, (ii) removing the "Z" designation, (iii) adding "SRP" for "serpin"-nomenclature consistent with recent naming of Arabidopsis serpins [39]and (iv) adding the one-letter codes for the amino-acid residues corresponding to the canonical $\mathrm{P} 2-\mathrm{P1}^{\prime}$ sequence of the RCL in each case. The assignment of these residues was determined by counting residues $C$-terminal to the highly conserved Glu at P17. For example, the rice serpin encoded at the locus Os03g41419 was given the name OsSRP-LRS (Additional file 1: Table S1). Corresponding gene names are given in italics. The reactive-centre sequence was adopted in preference to the numbering system used previously [22] because the former contains functional information lacking in the latter. The inclusion of "SRP" in the new alternative names will also assist readers in identifying proteins as serpins.

\section{Revised rice-serpin gene models}

We attempted to revise sequence models when they did not fit the transcript-based evidence. We also assumed that if no transcript evidence was available, the gene model should be consistent with the gene models for the other serpins in the same species. Based on the analysis conducted here, the putative products encoded by serpin genes OsSRP-LGC (Os01g56010), -FRS (Os03g41438), -PTY (Os04g45110), -PGY (Os04g45120), -FAS (Os11g12460), -GMS (Os11g12520), -LLS (Os11g13530) and -FLC (Os11g13540) had been annotated with correct protein lengths in the Rice Genome Annotation Project database (http://rice.plantbiology.msu.edu/). OsSRP-QKG (Os01g16200) had a predicted protein length of 423 aa in the database, suggesting that this serpin would have a $\mathrm{N}$-terminal extension relative to most of the other serpins. To our knowledge no transcript evidence was available to support this extension. Since an alternative START codon was available to give a protein with a length compatible with almost all the other rice serpins, 25 residues were removed from the $N$-terminus of OsSRP-QKG for the sequence alignment so that the protein sequence begins with MAPP rather than MAAL (Figure 1). The serpin OsSRP-LRS (Os03g41419) was incorrectly annotated in the database as producing a protein of 719 aa in length. The serpin sequence was edited by retaining the 137 residues at the $\mathrm{N}$-terminus from MADD to FQTK but removing 72 residues (corresponding to two erroneous exons) starting from WLLL and ending in TSGK. The following 252 residues beginning at AAEV and ending at VGHV were retained. Finally, the last seven residues which, according to the erroneous gene model, are AAEVLGQ, were changed to VNPLLAA in accordance with translation of an available cDNA (accession no. AK243629). Thus the total length of OsSRP-LRS is $137+252+7=396$ residues, consistent with the protein length predicted elsewhere based on translation of ESTs and cDNAs [22]. The Rice Genome Annotation Project database indicated that OsSRP-LRS (Os03g41419) contained four introns but the corrected sequence contains only one intron, consistent with the other rice serpins (Figure 1). The fifth exon in the erroneous gene model is associated with a separate cDNA sequence (accession no. AK121227). When translated, this cDNA gives a sequence beginning with LYFK and ending with LLAV, with a total length of 218 aa. This represents a partial second serpin sequence and includes an RCL distinct from that encoded by exon 4 in the original gene model.

OsSRP-PLP (Os11g11500) had a predicted protein length of 439 aa in the database. The $N$-terminal extension (relative to the other rice serpins) is supported by a full-length cDNA sequence (AK287588) and several ESTs (including CI370534 and CI410938). This is the only rice serpin for which a full-length cDNA supports a substantial $N$-terminal extension. For the sequence alignment (Figure 1), the first 45 residues (MQVSSYLRRALRRPPFPAGDANHRRLSSAPAPKPEAP AEAMPPPP) were removed from the $N$-terminus so that 


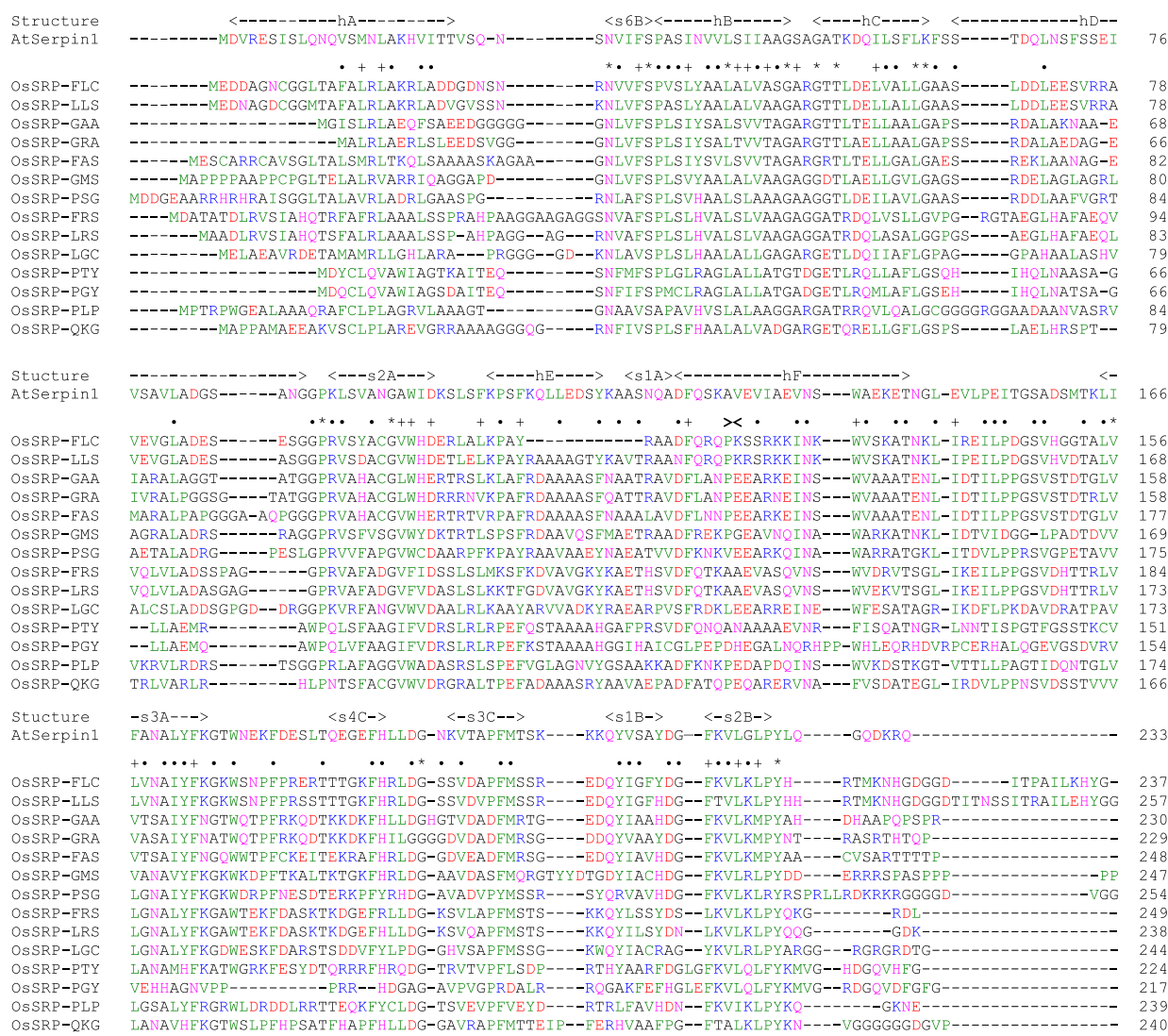

Stucture
AtSerpin1

$\begin{array}{cl}<-s 3 B--> & <-----h G------> \\ -- \text { ESMYFYLPDANNG---ISDLIDKIVSTPG } & -\end{array}$ $<\mathrm{hH}->$

$<--s 2 \mathrm{C}---><-s 6 \mathrm{~A}--><--\mathrm{hI}-->$

OSSRP-FLC

OSSRP-LLS
OSSRP-GAA

OSSRP-GRA

OSSRP-FAS

OSSRP-GMS

OSSRP-PSG

OSSRP-FRS

OSSRP-LRS

OSSRP-LGC

OSSRP-PTY

OSSRP-PGY

OSSRP-PLP

Structure

FLDNHI-

.. + +****++.

$+*+*$ * $+0^{+} \cdot+$

ENVGISMYIFIPDARDG---IPALVDKMAVASSGTASSSELLRDHR-PGRRRIKVGDLRVPRFKVSFYSEMNEVLKGMGIGAAFDVGKVDISGMID----- 328

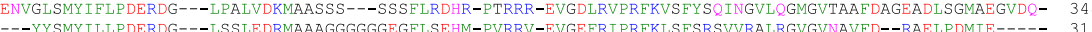
---QYSLCVFLPDKRNG---IWTLADRMEAGGG---_EVFTREHM-PEKRV-KVGEFRTPRFKLSFDGSTKTALOGVGVRAVFDPAAADLSDVIFEGNS- 316 ---RYSMYVFLPDERDG---IWSLEDRMAAGGE-----GELREHT-PERRV-EVGEFRI PREKLSFDDSVVGALQRLGVRDVFKPFVADLADVLEAENSG 335 STPRESLCVFLPDALDG---IWDLIDEIASTPG------FLQAKL-PTRHA-SVGELKL PKFKLTFSGDIAGVLRGLGLDATFS DGEADF SKMVEDDG-- 334 EFTRYAMAIFLPDARDG---LRGLVERMASRPG------FLHEHM-PAAWPVPVGEFRVPKFKVSCGGSVVGALEQLGLRLPFSPELADLSDMVEDDG-- 342

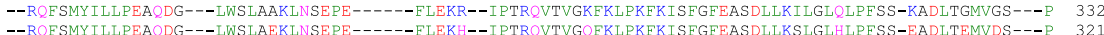

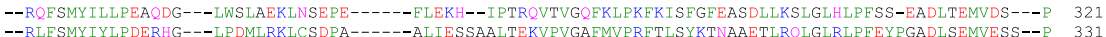
$\begin{array}{lll}\text {--RLFSMY IYIPDERHG---LPDMLRKLCSDPA------ALIESSAALTEKVPVGAFMVRETLSYKTNAAETLRQLGLRLPFEYPGADLSEMVESS--P } & 331 \\ \text {-APCECMLVELPIKRDG---LRHLLRMAVTEPD------EVMRCV-PRSEQ-EVSPCMVPKFKFSSELDARGALAKLGLGAPFDPLAADLSRMAVSV-NT } & 311\end{array}$

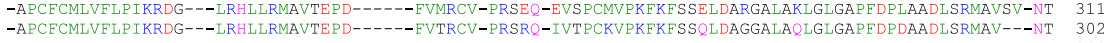
--RKESMYIFLPDDHDG---LFELTQKIFSEPM------ELEOHL-PTEKC--HVGISVPNFKISFQIDVKDFLKDUGLELPDLR EA

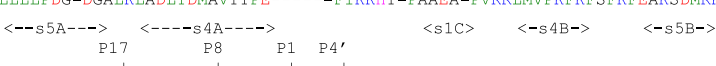

AtSerpin1

-GKNLCVSNIFHKACIEVNEEGTEAAAASAGVIKLR GLLM----EEDEIDFVADHPFLLVVTENITGVVLFIGQVVDPLH------------------- 39

OSSRP-FLC

OSSRP-LLS

OSSRP-GAA

OSSRP-GRA

OSSRP-FAS

OSSRP-GMS

OSSRP-PSG

OSSRP-IRS

OSSRP-LGC

OSSRP-PTY

OSSRP-PGY

OSSRP-PLP

OSSRP-QKG

OSSRP-FLC

OSSRP-LLS

OSSRP-GAA

OSSRP-GRA

OSSRP-FAS

OSSRP-PSG

OSSRP-FRS

OSSRP-FRS

OSSRP-IGC

OSSRP-PTY

OSSRP-PGY

OSSRP-PLP

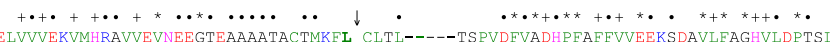

-GELVVEKVMHRAVVEVNEEGTEAAAATACTMKFL

RGGLVVEVHRAVVEVNEEGTEAAASTACTIRLI SMSY-----PEDFVADHPFAFFVVEETSGAVLEAGHVIDPTSSSE---0--0--- 424

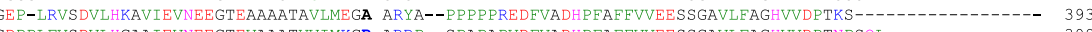

D.
D.

GRRPLSMRSLVHKAVIEVNEEETEAAASAINMVCGM SMTP--EPRPVPVDFVADHPFAFFVTFETTGAVVEAGHVIDPSSTAGALDDDDDDDEFVVMGC GWPLFVGDIQHKAVIEVNEEGTVAAAATMTRMLPS GVPP-----PPVDFVAEHPFAYFIVEEMSSAVVEAGHTVDPSNE- -

RHNLFVSSLFHKSFVQVDEEGTEAAAASAAVVSFR SAPV-------TVDFVADHPFLFLIREDMTGVVLFIGHVVNPLI-- -

GKNLFVSSVFHKSFVEVNEEGTEAAAATAAVITLR SAPI-------AEDFVADHPFLFLIQEDMTGVVLFVGHVVNPLIAA

EAEKIVVSAVYHESFVEVNEEGTEAAAATAVVMTLG CAAP--SAPVHVVDFVADHPFMFLIKEDLTGVVVEAGQVTNPSSST - -

PPAGLYVSTMROKCAVEVDEFGTTAVEAMYSPSSPG YSPGYQPPRPP DMSFVAEHPFMFATVEYKKAQVLFLGHVMDPSKEDQ----------- 392

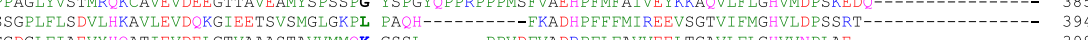

GGDGLFIAEVYHQATIEVDELGTVAAASTAVVMM $Q K$ GSSL------PPVDFVADRPFLFAVVEELTGAVLFLGHVVNPLAE--

LRYLIDRCMAFVGV 445

Figure 1 (See legend on next page.) 
(See figure on previous page.)

Figure 1 Amino acid sequence alignment for the 14 full-length serpins in rice (Oryza sativa cv. Nipponbare) with the Arabidopsis AtSerpin 1 sequence and secondary structure. The Arabidopsis AtSerpin 1 sequence and secondary structure assignments were from the X-ray crystal structure [PDB: 3LE2] [7]. Rice sequences were obtained from the Rice Genome Annotation Project (Michigan State University), edited where required according to the text and aligned using ClustalW (accurate) using default parameters (gap opening penalty $=10$, gap extension $=$ 0.05, Blosum30 series protein weight matrix). Note the sequence shown for OsSRP-PLP does not include the 45-residue N-terminal extension supported by full-length cDNA evidence as described in the text. Residues are coloured according to physico-chemical properties: Black, small; Green, medium-sized and large hydrophobic; Pink, polar; Red, negatively charged; Blue, positively charged [47]. ${ }^{*}$, identical residues in all rice serpins; +, conserved residues in all rice serpins (according to colour scheme above); $\bullet$ conserved residues in 11-13 of the 14 rice serpins (according to colour scheme above); $><$, intron-exon boundary for all rice serpins in alignment except OsSRP-QKG, which lacks an intron.

the sequence began at MPTRPW and contained 394 aa residues, consistent with the protein length predicted earlier [22]. OsSRP-PSG (Os11g11760) was annotated in the database as producing a protein of 452 aa. This sequence was edited by removing the 30 aa residues that corresponded to an (invalid) translation of the intron-found at a conserved site [22] - in this gene and the five contiguous and nonconserved Ala residues (almost certainly an artefact) that were present later in the sequence. This gave the predicted protein a length of 417 aa (Figure 1). OsSRP-PTY (Os11g12410) and -PGY (Os11g12420) were annotated in the database as containing two introns and producing proteins of 510 aa and 524 aa, respectively. No full-length cDNAs support these models. The corrected protein lengths are 393 and 398 aa for OsSRP-PTY and -PGY, respectively, with both of the corresponding genes containing one intron. Relative to the database sequence, 117 aa residues were removed from the $N$-terminus of OsSRP-PTY and 126 aa residues from the $N$-terminus of OsSRP-PGY [22]. The current gene model for OsSRP-GMS encodes a serpin with a substantial $C$-terminal extension. There is no STOP codon (TAG, TAA or TGA) earlier in the sequence than the existing one (TAG, which ends the OsSRP-GMS sequence at FVGV; Figure 1).

\section{Amino-acid sequence alignment and phylogenetic analysis}

Alignment of the edited amino-acid sequences showed several highly conserved regions (Figure 1), as was expected based on alignments of serpins from other organisms. These regions include the hinge of the $\mathrm{RCL}$, the breach, shutter and other regions critical for generation of the serpin fold [48]. The majority of differences between the rice serpin sequences are the presence/absence of additional amino-acid residues between conserved regions. Disregarding the putative 45-aa $N$-terminal extension of OsSRP-PLP (as discussed above), the $N$-terminus of the serpins (Figure 1 - up to the Asn conserved in all 14 serpins in the middle of the first line) varies in length from 19 to 44 aa. Two of these serpins have three consecutive negatively charged residues, which conceivably could serve as a binding motif for interacting molecules. The $C$-terminus of OsSRP-GMS (Os11g12520) is substantially longer (by $\sim 30$ residues) than the $C$ termini of any of the other serpins and includes a sequence of eight negatively charged residues, which might also serve as a binding motif.

Features of the AtSerpin1 X-ray crystal structure include a relatively long loop joining $\beta$-strands $\mathrm{s} 2 \mathrm{~B}$ and

\begin{tabular}{|c|c|c|c|c|c|c|c|c|c|c|c|c|c|c|c|}
\hline Locus & P2-P1' & FLC & LLS & $\mathrm{GAA}$ & GRA & FAS & GMS & PSG & FRS & LRS & LGC & PTY & PGY & PLP & QKG \\
\hline Os11g13540 & FLC & 100 & & & & & & & & & & & & & \\
\hline Os11g13530 & LLS & 86 & 100 & & & & & & & & & & & & \\
\hline Os11g12410 & GAA & 52 & 54 & 100 & & & & & & & & & & & \\
\hline Os11g12420 & GRA & 54 & 54 & 80 & 100 & & & & & & & & & & \\
\hline Os11g12460 & FAS & 49 & 50 & 74 & 71 & 100 & & & & & & & & & \\
\hline Os11g12520 & GMS & 50 & 52 & 53 & 53 & 50 & 100 & & & & & & & & \\
\hline Os11g11760 & PSG & 52 & 52 & 48 & 49 & 49 & 49 & 100 & & & & & & & \\
\hline Os03g41438 & FRS & 45 & 44 & 43 & 42 & 41 & 41 & 41 & 100 & & & & & & \\
\hline Os03g41419 & LRS & 48 & 48 & 47 & 45 & 44 & 42 & 42 & 87 & 100 & & & & & \\
\hline Os01g56010 & LGC & 45 & 44 & 42 & 41 & 42 & 40 & 45 & 49 & 52 & 100 & & & & \\
\hline Os04g45110 & PTY & 35 & 34 & 33 & 34 & 32 & 33 & 36 & 35 & 36 & 34 & 100 & & & \\
\hline Os04g45120 & PGY & 27 & 26 & 26 & 25 & 24 & 25 & 29 & 28 & 27 & 25 & 63 & 100 & & \\
\hline Os11g11500 & PLP & 37 & 37 & 38 & 36 & 38 & 37 & 38 & 39 & 40 & 35 & 32 & 25 & 100 & \\
\hline Os01g16200 & QKG & 43 & 44 & 43 & 43 & 40 & 40 & 41 & 39 & 42 & 39 & 40 & 30 & 36 & 100 \\
\hline
\end{tabular}

Figure 2 Amino acid identity matrix for the 14 full-length serpins in rice. An edited amino acid alignment (Figure 1) was entered into ClustalX v2.0 as an .aln file and the percent identities calculated by the program. Colours represent bands of percent identity: red, 20-39\%; orange, 40-59\%; yellow, 60-79\%; green, 80-99\%. 


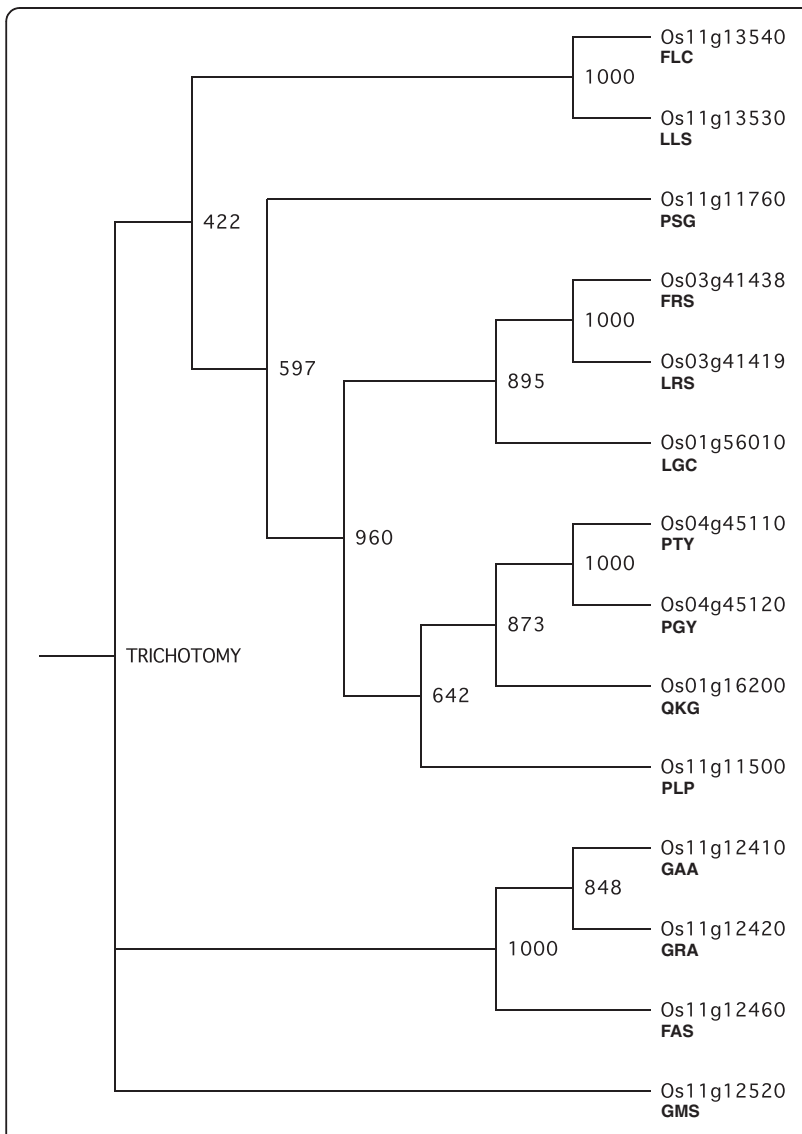

Figure 3 Phylogenetic tree based on protein sequences of the 14 rice serpins. A neighbour-joining tree using the 14 serpins in rice was constructed using the ClustalX v2.0 program and presented using TreeView X v0.5.0 [43]. Bootstrap values from 1000 bootstrap trials are given on the nodes. Locus numbers and $\mathrm{P} 2-\mathrm{P} 1^{\prime}$ codes are used as labels for the serpins.

s3B, which contains a plant-specific motif between Tyr225 (the conserved breach tyrosine) and the hydrophobic core residue Phe-234 [7] - see Figure 1 for these residues. An alignment of 67 expressed plant serpin sequences showed that the motif YXXGXDXRXF was present in 54 of these sequences, with an additional eight sequences containing conservative variations of the motif [7]. The conserved Asp-230 and Arg-232 of this motif in AtSerpin1 form a network of hydrogen bonds that links the s2B-s3B junction to the loop connecting helix $\mathrm{hD}$ and $\beta$-strand s2A. These interactions stabilise this loop region, which is otherwise disordered in many other serpin structures [7]. The breach Tyr is present in all the 14 rice serpins while the hydrophobic core Phe is found in eight of the 14 sequences, with another hydrophobic residue (Tyr or Leu) in the other six serpins (Figure 1). The only rice serpins in which the motif is conserved-including the Asp and Arg mentioned above-are OsSRP-FRS and -LRS (putative orthologues of AtSerpin1). The limited conservation of the plant-specific motif in rice serpins may be partly a reflection of the somewhat biased nature of the 67 serpin sequences mentioned above, since nearly half of these sequences were those of LR serpins. While the AtSerpin1 sequence between (and including) the conserved Asp-230 and Arg-232 is 10 amino acids long (see motif above), the length of the corresponding region in the rice serpins ranges from 10 amino acids (OsSRP-FRS and -LRS) to 28 amino acids in OsSRPFLC and 36 amino acids in OsSRP-LLS. Additional X-ray crystal structures of plant serpins will be required to determine whether the variation in the length of this loop is structurally important.

The degree of identity between the rice serpins ranged from $24 \%$ to $87 \%$, with an average value for all pair-wise comparisons of $42.9 \%$ (Figure 2). The pairs of serpins with the highest levels of identity were OsSRP-LRS and -FRS (87\%) and OsSRP-LLS and -FLC (86\%). Members of these pairs have similar reactive centres and represent neighbouring genes (on chromosomes 3 and 11, respectively), suggesting that they arose through relatively recent gene duplications, as supported by the phylogenetic analysis (see below).

Phylogenetic analysis of the rice serpins based on amino-acid sequences resulted in a trichotomy at the tree base, with one of the serpins (OsSRP-GMS; Os11g12520) alone on one of the three main branches (Figure 3). The serpins on the top-most main branch of the tree were moderately well resolved into several smaller clades (bootstrap values 422 to 960 ) while those on the middle branch were very well resolved (boot-strap value 1000) (Figure 3).

\section{Detection of putative orthologues of Oryza sativa cv. Nipponbare serpin genes in other varieties of Oryza sativa and other species of Oryza}

As the genome sequences of the other varieties and wild species are not known, a genomic PCR experiment was conducted to test whether primers designed to amplify a fragment of eight of the serpin genes in O. sativa cv. Nipponbare could be used to detect serpin genes in these rices. Only serpin genes with sequences at the sites of primer hybridisation identical or near-identical to those in Nipponbare were likely to be amplified by the primers.

Amplicons were generated with primers for OSSRP$L G C,-P T Y,-P L P$ and $-F L C$ in all of the rices (Figure 4). OsSRP-QKG primers amplified a product of the expected size in all of the rices except $O$. australiensis, while OsSRP-LRS was not amplified in cv. Reiqiz. OsSRP-FRS was not detected in $O$. australiensis and $O$. meridionalis. OsSRP-FAS was amplified in cv. Nipponbare, Doongara and Kyeema. Limited amplification using the OsSRP-FAS primers in Langi, Opus, Quest, Reiqiz, O. australiensis and $O$. meridionalis suggested that the hybridising sequences were imperfect matches to the primers in these varieties/species. 

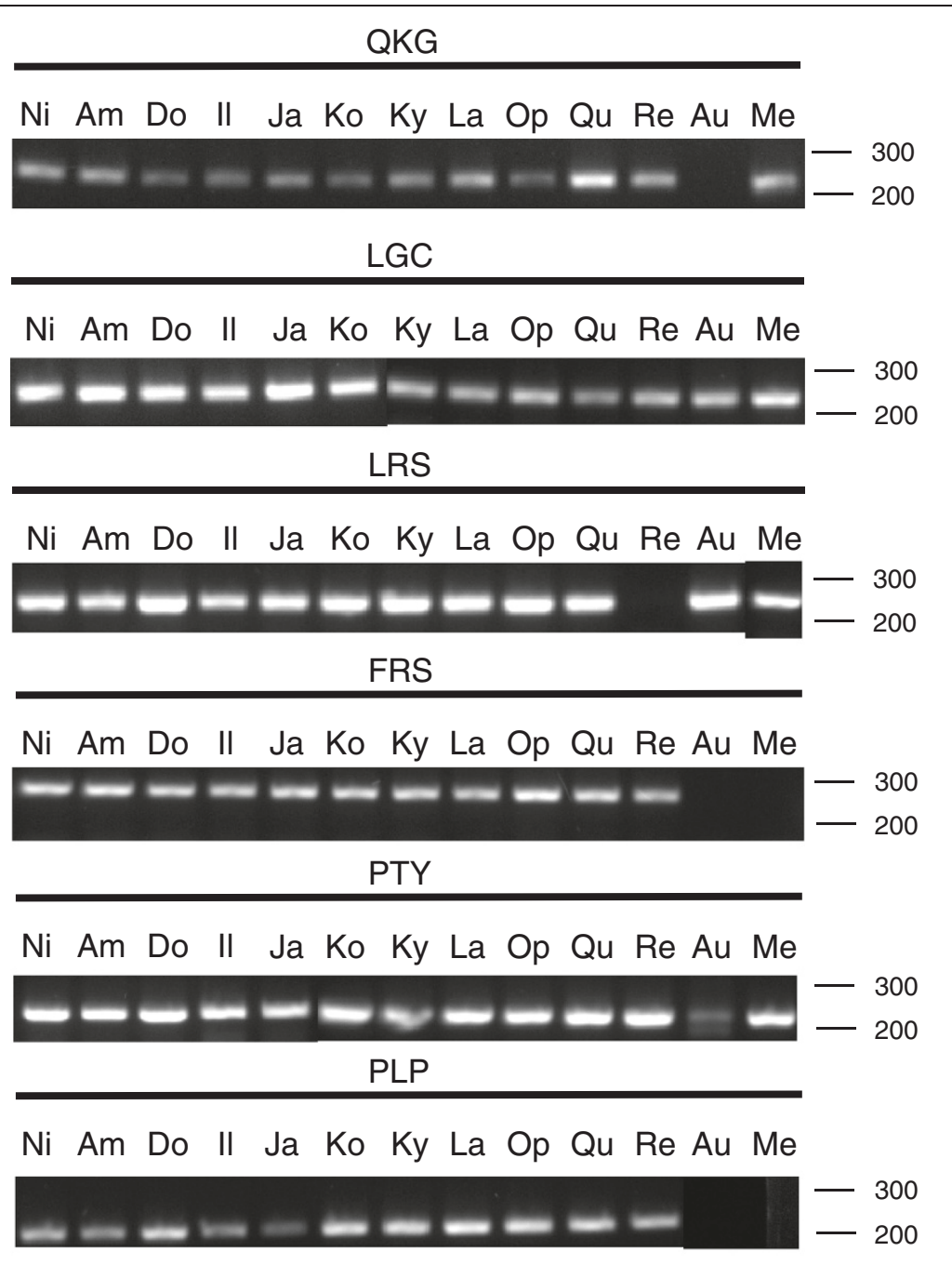

\section{Fas}

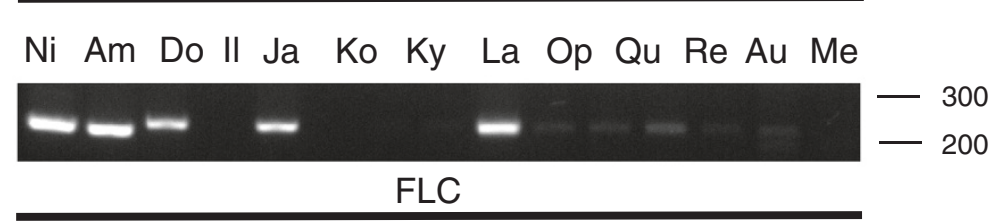

Ni Am Do II Ja Ko Ky La Op Qu Re Au Me

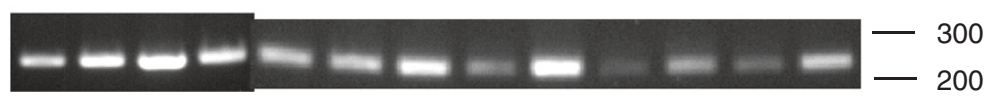

Figure 4 Evidence for conservation of serpin genes in a variety of $O$. sativa cultivars and wild Oryza species. Primer sets used to amplify eight serpin genes in Nipponbare (labelled according to P2-P1' sequence) were used to amplify segments of putatively corresponding genes in

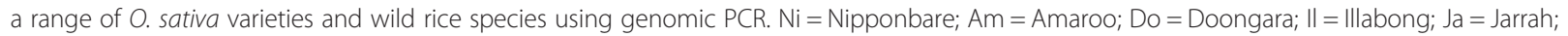
Ko = Koshihikari; Ky = Kyeema; La = Langi; Op =Opus; $\mathrm{Qu}=\mathrm{Quest} ; \mathrm{Re}=$ Reiziq; $\mathrm{Au}=\mathrm{O}$. australiensis; and $\mathrm{Me}=\mathrm{O}$. meridionalis.

Rice serpin gene expression data from published microarray and proteomics studies

The Rice GE: Gene Expression Analysis microarray data from the Salk Institute Genomic Analysis Laboratory (SIGnAL) was examined for 12 of the 14 full-length serpin genes [22]; genes OsSRP-GRA (Os11g12420) and -GMS (Os11g12520) were not represented among the genes in the microarray. Only some of the serpin genes displayed levels of expression above background noise (i.e. values $>500$ ). The highest expression levels for all serpin genes in 


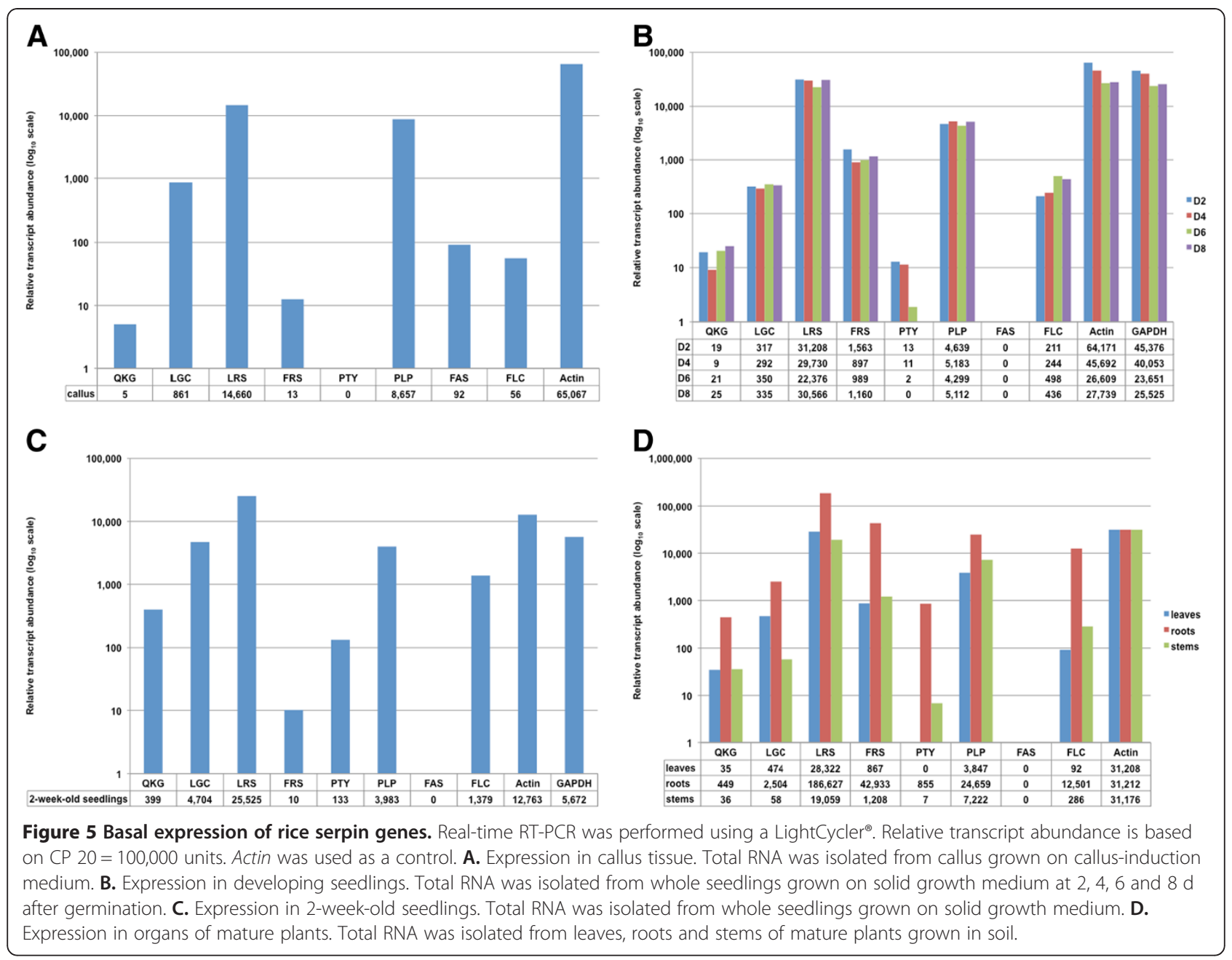

the microarray data were found for OsSRP-LGC (Os01g56010) in seeds during late development; i.e. Stage 4 (11-20 dap) and Stage 5 (21-29 dap), mirroring the expression of the barley-grain serpins BSZ4 (HorvuZ4) and BSZ7 (HorvuZ7) [49,50]. Significant expression of this gene was also observed for rice roots treated with transzeatin (a cytokinin) after $30 \mathrm{~min}$ and still after $120 \mathrm{~min}$, hinting at involvement of serpins in processes relating to cell division, consistent with the results obtained for AtSRP2 (At2g14540) and AtSRP3 (At1g64030) in Arabidopsis. OsSPR-LRS (Os04g41419) was expressed at substantial levels (values $>500$ ) for the majority of the conditions included in the SIGnAL microarray, with expression associated with grain development increasing from Stage 1 (0-2 dap) through to Stage 3 (5-10 dap) and then falling away through Stages 4 and 5. Thus it appears OSSRP-LRS was expressed at an earlier stage of grain development than was the OsSRP-LGC gene. OsSRP-PLP (Os11g11500) was associated with significant levels of expression in the shoot apical meristem (SAM) and at only the latest stage in grain development (Stage 5). It was also expressed at substantial levels (values $>500$ ) in the ovule. OsSRP-LLS (Os11g13530) was expressed at low levels (values $<500$ ) except that expression was higher in Stage 4 of grain development (although at a value associated with a large estimate of error).

OsSRP-QKG (Os01g16200), -FRS (Os03g41438), -PTY (Os04g45110), -PGY (Os04g45120), -PSG (Os11g11760) and -FAS (Os11g12460) were associated with expression values below background noise for all conditions and thus no confident conclusions could be drawn regarding differential expression for these genes.

Proteomics experiments have identified serpins OsSRP-LGC in root and OsSRP-LRS in seed using MudPIT analysis [51]. Overall there is rather little proteomics evidence for the expression of rice serpin genes. This is somewhat surprising considering the high levels of expression of some of the rice serpin genes at the transcript level, particularly OsSRP-LRS. It is possible that some rice serpin transcripts (while abundant) are poorly translated, as suggested for the LR serpin gene in barley (encoding BSZx) [52]. 


\section{Basal expression analysis of eight rice serpin genes in callus, developing seedlings, mature tissues and developing seeds}

Semi-quantitative RT-PCR experiments were performed as a prelude to real-time (qRT-PCR) experiments. These two forms of transcript analysis were run with independent samples (plants grown independently).

Real-time analysis of serpin gene expression in callus tissue showed that OSSRP-LRS and -PLP were the most highly expressed, followed by OsSRP-LGC (Figure 5A). OsSRP$F A S,-F L C,-F R S$ and $-Q K G$ were scarcely expressed in callus tissue and no expression was detected for OsSRPPTY (CP >36). The pattern of serpin gene expression in callus tissue was very similar to that of 2-d-old developing seedlings (Figure 5B), for which transcript levels relative to Actin were almost the same as in callus.

For whole seedlings during development, semiquantitative RT-PCR using 35 cycles showed that serpin genes OsSRP-QKG, -LGC, -LRS, -FRS, $-P T Y,-P L P$ and -FLC were expressed in seedlings at all stages examined (2, 4, 6 and $8 \mathrm{~d}$ after germination; results not shown). OSSRP-LRS and -PLP gave product-band intensities higher than those for any of the other serpin genes and similar to those for Actin. OsSRP-QKG, -LGC, -FRS, $-P T Y$ and -FLC appeared to be expressed at low levels during seedling development and OsSRP-FAS did not appear to be expressed (results not shown). The semi-quantitative data concurred with results of the real-time analysis (Figure $5 \mathrm{~B}$ ). With the exceptions of OsSRP-PTY and -FLC, the expression patterns of the eight selected rice serpin genes did not change significantly during the first $8 \mathrm{~d}$ of seedling development. The very low level of OsSRP-PTY expression decreased almost six-fold between D4 and D6 and was not detected at D8, although these levels of expression were near the limits of detection. In contrast, OSSRP-FLC transcript was slightly more abundant in D6 and D8 than it was in D2 and D4. No expression $(\mathrm{CP}>36)$ was detected for
OsSRP-FAS in the course of early seedling development (Figure 5B).

Real-time analysis of basal expression of the eight serpins in 2-week-old seedlings showed that, as in younger seedlings (Figure 5B), OsSRP-LRS was the most abundantly expressed rice serpin gene (Figure $5 \mathrm{C}$ ). In 2week-old seedlings the expression level of OsSRP-LRS was even higher than those of the housekeeping genes, Actin and GAPDH. Other relatively highly expressed rice serpin genes in 2-week-old rice seedlings were OsSRP$L G C$ and -PLP. OsSRP-LGC expression was an order-ofmagnitude higher in 2-week-old seedlings than it was in 2 to 8 -d-old seedlings, whereas OsSRP-FRS expression was an order of magnitude lower in 2-week-old seedlings (Figure $5 \mathrm{C}$ ) than it was in 2 to 8 -d-old developing seedlings (Figure 5B).

For roots, root tips, stems and leaves of mature rice plants, semi-quantitative RT-PCR using 35 cycles indicated that OsSRP-LGC, $-L R S$ and $-P L P$ were expressed at higher levels than any of the other serpin genes (results not shown). OSSRP-LRS gave product-band intensities comparable with those of Actin, while OsSRP-QKG appeared to be expressed in all of the mature tissues but at a very low level (extremely faint bands). OsSRP-FRS appeared to be expressed at a higher level in the stem than in the other tissues and OSSRP-FLC was more highly expressed in the root tip, while OsSRP-PTY appeared to be expressed only in the root tips. OsSRPFAS did not appear to be expressed in any of the mature tissues (results not shown). The semi-quantitative data were supported by results of the real-time analysis (Figure 5D). OsSRP-LRS was the most abundantly expressed rice serpin gene in all three organs, with OSSRP-FRS and -PLP being the two other highly expressed serpin genes. OsSRP-FLC, $-L G C,-Q K G$ and $-P T Y$ were expressed at very low levels. All serpin genes were expressed at their highest levels in roots when

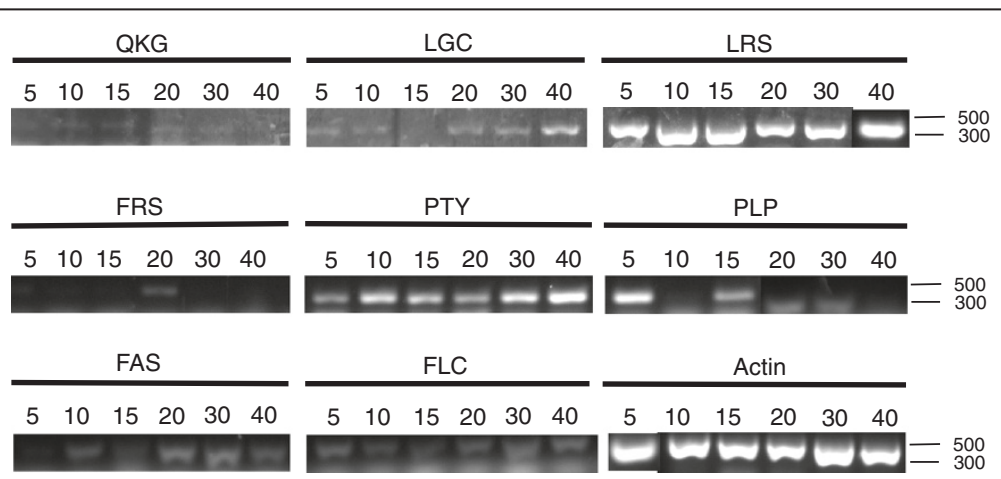

Figure 6 Expression of eight serpin genes in developing seeds. Semi-quantitative RT-PCR was used to study the expression of eight serpin genes (labelled according to P2-P1' sequence) in O. sativa cv. Nipponbare developing seeds collected 5, 10, 15, 20, 30 and $40 \mathrm{~d}$ after anthesis. Actin was used as a control. 
expression levels were normalised to those of Actin. No expression signal was detected for OsSRP-PTY (CP: >36) in leaves and (again) for OsSRP-FAS in any of the organs (Figure 5D).

Serpin gene expression was analysed using semiquantitative RT-PCR in developing seeds at 5, 10, 15, 20, 30 and $40 \mathrm{~d}$ post anthesis (Figure 6). OsSRP-LRS was expressed during the entire seed development process at about the same level as Actin. OsSRP-PTY was also strongly expressed during seed development. OsSRP-PLP appeared to be expressed at a relatively high level $5 \mathrm{~d}$ after anthesis and then at a lower level as the seed matured. There was a low level of expression of OsSRP$Q K G,-L G C,-F R S,-F A S$ and $-F L C$ in most stages of seed development (Figure 6).

\section{Discussion}

Plant serpin nomenclature

The assignment of reactive-centre residues in the new alternative names for the rice serpins is based on canonical positions, which means the $\mathrm{P} 1$ residue is identified by counting 17 residues from the highly conserved Glu (normally at P17). These assignments are tentative because some animal serpins have 16 residues between the conserved Glu and the experimentally determined P1 residue. For the vast majority of serpins, however, the physiological target proteinase is expected to cleave at the canonical P1, not at P2 (or elsewhere). We recommend that the terminology of a serpin (using the suggested nomenclature) would be changed if the physiological target proteinase were found to cleave at a residue other than the canonical P1. We also recommend that the terminology would not change on the basis of results from testing nonphysiological proteases against the serpins (e.g. a mammalian chymotrypsin versus a rice serpin). In summary, the name of the serpin would ultimately depend on experimental evidence for the identity of the cleavage site but only with a proteinase that was shown to be the major physiological target. Any change in the suggested nomenclature remains a long-term prospect because currently there is only a single serpin-proteinase partnership established in vivo in plants (Lampl et al., 2010).

The reactive centre $\mathrm{P} 2-\mathrm{P}^{\prime}$ residues are different in each of the rice serpins (Additional file 1: Table S1). The P1 residues include positively charged (Arg and Lys), small (Ser and Ala) and medium-sized hydrophobic residues (Met and Leu). For the putatively inhibitory serpins, the P2 residues are Gln, Leu, Phe, Pro and Gly-none being charged. All of the inhibitory serpins have a small residue (Ala, Cys, Gly, Ser) at P1' (Additional file 1: Table S1), consistent with the majority of animal serpins.

The naming system adopted in this paper could be extended to other plant species to enable easy matching or differentiation between serpins with identical or similar reactive-centre sequences. If a species contained more than one serpin with the same P2-P1' sequence, the serpins could be named in the same way but with a number after the $\mathrm{P} 2-\mathrm{P}^{\prime}{ }^{\prime}$ designation. Meanwhile, there is a danger that confusion may arise if researchers name the first serpin to be characterised in any particular plant species using a two-letter abbreviation for the species and "Serpin1"; e.g. PsSerpin1 for pea (Pisum sativum) without reference to similarity to AtSerpin1.

Until homologous serpins in a range of plant species are shown to have the same function, it is unlikely the systematic naming system based on the (exclusive) membership of plant serpins to "Clade P" (among serpins generally), as proposed earlier [48], will be adopted. When that time

Table 3 Comparison of Arabidopsis and rice serpin reactive centres

\begin{tabular}{|c|c|c|}
\hline P1 residue type & Rice locus (P2-P1') & Arabidopsis locus (P2-P1') \\
\hline \multirow[t]{4}{*}{ Small $(A, C, G, S, T)$} & Os01g56010 (LGC) & At1g64030 (GCS) (AtSRP3) \\
\hline & Os11g11760 (PSG) & At2g14540 (TGS) (AtSRP2) \\
\hline & Os11g12410 (GAA) & At2g25240 (CTS) \\
\hline & Os11g12460 (FAS) & At2g35580 (GCR) \\
\hline \multirow{3}{*}{$\begin{array}{l}\text { Medium \& large hydrophobic } \\
(F, I, L, M, P, V, W, Y)\end{array}$} & Os11g12520 (GMS) & \multirow[t]{3}{*}{ At1g62170 (YLG) } \\
\hline & Os11g13530 (LLS) & \\
\hline & Os11g13540 (FLC) & \\
\hline Polar (H, N, Q) & & At2g26390 (PQC) \\
\hline Negatively charged (D, E) & & At3g45220 (KDM) \\
\hline \multirow[t]{4}{*}{ Positively charged $(K, R)$} & Os01g16200 (QKG) & \multirow[t]{4}{*}{ At1g47710 (LRG) (AtSerpin1) } \\
\hline & Os03g41419 (LRS) & \\
\hline & Os03g41438 (FRS) & \\
\hline & Os11g12420 (GRA) & \\
\hline
\end{tabular}

Amino-acid residues are divided into groups based on physico-chemical properties [47]. The P1 residue is shown in bold. Putatively non-inhibitory serpins OsSRP-PLP, -PTY and -PGY [22] are excluded from the table. 
arrives, functionally characterised, conserved plant serpins might be named SERPINP1, SERPINP2, etc., in the same fashion as (for example) the animal serpin $\alpha_{1}$-antitrypsin, which belongs to "Clade A", is named SERPINA1.

\section{Phylogeny of the rice serpins}

With the exception of the trichotomy at the base, the phylogenetic analysis produced a tree (Figure 3 ) suggesting varying levels of relatedness among the 14 rice serpin genes. Fine branching on the right of the phylogenetic tree with bootstrap values of 848 and 1000 showed closely related serpins that presumably resulted from relatively recent gene duplications. The differences in the reactivecentre sequences of these otherwise closely related serpins might reflect a need to broaden the inhibitory specificity of the rice serpin complement for defence against digestive proteinases from insects or pathogens.

\section{Conservation of serpin genes in Oryza}

Genomic PCR using Nipponbare primers suggested that many of the eight serpin genes tested are similar in the rices examined to those in Nipponbare (Figure 4). The absence of a product for a particular gene does not imply that the particular rice does not contain this gene; rather, it indicates that if the gene is present it has changed substantially so that primers are unable to anneal to it. It is noteworthy, however, that Oryza australiensis gave PCR amplicons for the fewest serpin primers, consistent with its EE genome (cf. AA genome in O. sativa and $O$. meridionalis).

It is likely that some plant serpins are involved in the regulation of endogenous proteinases while others act directly to inhibit digestive proteinases of insects or pathogens $[21,22]$. We would expect the reactive centres of the former serpins to be more highly conserved than those of the latter because the pests and pathogens that attack plants in distinct environments would presumably employ different digestive proteinases with distinct proteolytic specificities.

\section{Comparison of the Arabidopsis and rice serpin complements}

Genomic comparisons between Arabidopsis thaliana and rice are often instructive, as these model species represent the eudicots and monocots, respectively, and therefore almost all flowering plants. The Arabidopsis genome has eight genes encoding full-length serpins, compared to the 14 in the rice (Oryza sativa cv. Nipponbare) genome. We compared the diversity of reactive centres between these two species to determine the degree of identity of the putative inhibitory specificity of the serpins present (Table 3). For the putatively inhibitory serpins of both rice (11) and Arabidopsis (8), the predicted P1 residues have a range of physico-chemical properties but the serpin reactive centres of the two species do not match to a great extent (Table 3). For example, while four serpins in both rice and Arabidopsis have small residues at P1, Arabidopsis has one serpin with a negatively charged P1 residue (Asp), whereas rice has none. This serpin might conceivably inhibit a protease with caspase-like activity, such as the recently characterised subtilisin-like enzyme, phytaspase [53]. Unlike rice, Arabidopsis has one serpin with a Gln at P1, a polar residue found in most of the grain serpins in wheat [34] and rye [54] and also in specific serpins from several other plant species such as cotton [55]. These differences in serpin complement may make it difficult to predict the function of a particular serpin in rice based on information obtained from Arabidopsis or vice versa. The clear exception to this is that both Arabidopsis and rice contain a single "LR" serpin, namely AtSerpin1 and OsSRP-LRS, respectively, and rice also contains the serpin OsSRP-FRS with a very similar reactive centre. Two other rice serpins, OsSRP-QKG and GRA, have positively charged residues at P1 but have no matches in the Arabidopsis genome (Table 3).

Notwithstanding the somewhat greater reactive-centre diversity of the Arabidopsis serpins compared to that of rice, the substantial differences in the reactive centres of the rice serpins are reminiscent of the oat-grain serpins [32] and unlike the glutamine-rich reactive centres in serpins of wheat [34] and rye [54] grain.

\section{Expression of rice serpin genes during development}

OsSRP-LRS, -PLP, -FRS and -LGC were expressed at much higher levels than those of the other serpin genes (OsSRP-FAS, -FLC, -PTY and -QKG) at different developmental stages and tissues (Figure 5A-D). With the exception of OsSRP-FRS, the identity of the highly expressed genes matched closely to those with greatest expression levels reported in the Rice GE: Gene Expression Analysis microarray data. A great range of basal expression levels was also found among six Arabidopsis serpin genes in a previous study [39]. A substantial range of expression levels has also seen among serpins detected at the protein level in mature cereal grains $[32,34,54]$. Thus different serpin genes within a single plant species feature promoters of vastly different strengths for basal expression.

Since the serpin genes are expressed in callus (Figure 5A), which is undifferentiated tissue, the serpins themselves are unlikely to be required only for processes involving cell differentiation. Moreover, since the pattern of expression among the eight serpin genes is similar in callus to that in plant tissues (i.e. in differentiated cells) it suggests that none of the serpins is required at substantially different levels for any processes found only in differentiated cells under basal conditions.

All selected serpin genes except OsSRP-FAS (no expression signal detected) were expressed at highest levels 
(relative to Actin) in roots (Figure 5D), which might be due to the involvement of one or more of the serpins in direct defence against pest/pathogen (exogenous) proteinases from soil-borne organisms. It is conceivable that higher concentrations are needed to protect against soilborne pests/pathogens than more dispersed pathogens that attack shoot tissues. Additionally, if the serpins (or at least a subset of them) are present to regulate endogenous proteases, perhaps the specific proteinases they regulate are in greater abundance in the roots than in the shoots.

The range of expression levels observed for the rice serpin genes might be due to a need for some serpins to play a role as defensive shields rather than (or as well as) acting as regulatory proteins, and hence to be present at relatively high concentrations [21,22]. As raised earlier, transcription of some of the serpin genes might produce mRNA molecules that are relatively poorly translated. Another reason may be that some of the serpin genes that are expressed weakly under basal conditions are substantially up-regulated by specific stresses or stages of plant development. Finally, some of the serpins might be required at relatively high concentrations under basal conditions (for example, to inhibit a specific endogenous proteinase) but at much lower levels when the target proteinase is required in the cell. Presumably each serpin has a defined half-life in the cell and thus if transcription is lowered, the concentration of serpin eventually falls.

\section{OsSRP-LRS and the possible functions of LR serpins in plants}

The P2-P1' sequence of OsSRP-LRS is an example of the most highly conserved reactive centre among serpins in the Plant Kingdom [22]. P2-P1' Leu-Arg-Xaa (where Xaa is a small residue) is present in at least one serpin in a large range of plant species (including AtSerpin1 from Arabidopsis) and perhaps in all plants [22].

OsSRP-LRS was expressed at a high level of mRNA at several developmental stages and in a range of tissues (consistent with the Rice GE: Gene Expression Analysis microarray data), possibly due to an as yet undefined constitutive function of the gene product. It may be that OsSRP-LRS is normally required to inhibit a protease involved in a specific stress response (when the stress is absent), as found for the Drosophila serpin, Spn43Ac, which negatively regulates a Toll signalling pathway controlling production of an anti-fungal peptide [56]. Another possibility is that OsSRP-LRS mRNA might be translated only under specific stress conditions, allowing the protein to be produced quickly from the abundant transcript.

OsSRP-LRS may function by inhibiting a digestive proteinase(s) in insects. Since the LR serpin from barley, BSZx, is known to inhibit proteases of different specificities at overlapping reactive centres in vitro [30], there is the strong possibility that OsSRP-LRS could also inhibit proteinases (including exogenous enzymes from pests) of different specificity; i.e. proteases with trypsin-like specificity at P1 Arg and chymotrypsin-like specificity at the canonical P2 Leu. OsSRP-LRS is likely to target the cysteine proteinase, oryzain, in vivo, as this enzyme is a putative orthologue of Arabidopsis RD21, the major proteinase target of AtSerpin1 [7]. The identities of the target proteinases for the other rice serpins remain unknown.

OsSRP-LRS has been shown to be present at the base of tillers in higher abundance in a relatively hightillering rice cultivar than in a cultivar that produces a relatively low number of tillers [46]. This suggested that this serpin might be involved in the regulation of tiller development. Unfortunately, this study was performed on only two cultivars-one high-tillering and one lowtillering rice-and thus the conclusions drawn need to be validated with a greater number of cultivars.

\section{OsSRP-PLP and the possible functions of non-inhibitory serpins in plants}

OSSRP-PLP was found to be the second most highly expressed serpin gene in developing seedlings, leaves and stems and callus (after OsSRP-LRS). These results, combined with the ubiquitous expression of OsSRP-PLP based on ESTs, strongly suggest that non-inhibitory serpins have functions in plants, of which there are many possibilities. Non-inhibitory serpins in animals act in diverse roles such as hormone carriage, as performed by corticosteroid binding globulin (CBG or SERPINA6)) and thyroxine binding globulin (TBG or SERPINA7), tumour suppression (maspin or SERPINB5), chaperone activity (HSP47 or SERPINH1) and protein storage

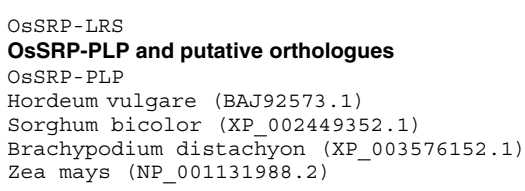

OSSRP-LRS

OSSRP-PLP

Sorghum bicolor (XP 002449352.1$)$

Brachypodium distachyon (XP_003576152.1)

Figure 7 Amino-acid sequence alignment of the reactive centre loop (RCL) sequences of putative orthologues of OsSRP-PLP in several grass species. BLAST-P searches of the non-redundant database at NCBI were conducted with the full-length OsSRP-PLP as the query sequence (09 Dec 2011). Accession numbers for the non-rice serpins are given in brackets after the species name. The RCL sequence of OsSRP-LRS is included for comparison. Refer to Figure 1 for residue colour code. 
(ovalbumin) [57]. The hinge region and reactive centre in the RCL of OsSRP-PLP are surprisingly well conserved in putative orthologues in other grass species (Figure 7), as observed earlier [22]. The conservation of the reactive centre ( $\mathrm{P} 4-\mathrm{P} 1^{\prime}$ GKPXP, where $\mathrm{X}$ is any residue) suggests that cleavage by a specific proteinase may be part of the mechanism by which this serpin functions.

Only some of the functions of non-inhibitory serpins in animals are possibilities for non-inhibitory serpins in plants. Plants use a substantial range of hormone (growth regulator) molecules, including brassinosteroids [58], which could conceivably bind to a site on a plant serpin. As plant serpins have already been shown to be present in the phloem sap [36] and to be graft-transmissible [59], there is the possibility that a hormone could then be transported in the phloem via binding to a serpin (and then released following RCL cleavage), as occurs for thyroxin in the blood [20]. While plants do not produce collagen (the protein acted on by HSP47), they do produce many extracellular proteins that need to be properly folded; thus chaperone activity is a possibility for the function of non-inhibitory plant serpins. Protein storage is another possibility for the function of OsSRP-PLP, which is the most likely function for the egg-white serpin, ovalbumin.

\section{Conclusions}

Models for the 14 genes encoding full-length serpins in the Oryza sativa cv. Nipponbare genome were confirmed or revised. Each of the 11 putatively inhibitory serpins has a unique reactive centre $\mathrm{P} 2-\mathrm{P}^{\prime}$ sequence although, of these, four have positively charged residues (Arg or Lys) at P1. Based on sequence analysis, one of the other three serpins, OsSRP-PLP, is very likely a non-inhibitory serpin while the non-inhibitory nature of the other two serpins (OsSRP-PTY and -PGY) is less certain. An amino-acid alignment (Figure 1) was used to construct a neighbourjoining phylogenetic tree (Figure 3), which indicated that 10 of the 14 serpins belong to a single clade. It also strongly suggested some of the serpin genes have arisen through relatively recent gene duplications.

At least one example of an LR serpin appears to be expressed in all plant species examined [22], including rice and Arabidopsis, and both these species have four serpins with small residues (Ala, Cys, Gly, Ser, Thr) at P1. Otherwise, however, the complement of serpins in rice is quite different to that found in Arabidopsis (Table 3). While rice has a greater number of inhibitory serpins, the greater diversity of the Arabidopsis P1 residues suggests specific Arabidopsis serpins may target proteinases that are not targeted in rice.

Amongst the serpin genes investigated, OsSRP-LRS and -PLP were found to be expressed at highest levels in callus tissue (Figure 5A), during early stages of seedling development (Figure 5B), in older seedlings (Figure 5C) and in organs of mature rice plants (Figure $5 \mathrm{D}$ ). In the latter, OsSRP-LRS was expressed at highest levels amongst the serpin genes investigated. All selected serpin genes except OsSRP-FAS (no expression signal detected) were expressed at highest levels relative to Actin in roots. OsSRP-LRS appears to behave like a housekeeping gene in that it is constitutively expressed under basal conditions but may be involved in regulation of oryzain activity in stress responses in a manner equivalent to the interaction between AtSerpin1 and RD21 in Arabidopsis. There is enormous scope for future studies to provide further functional information for the rice serpins.

\section{Additional file}

Additional file 1: Table S1. Serpins in rice (Oryza sativa cV.

Nipponbare). Serpin loci from the Rice Genome Annotation Project

(http://rice.plantbiology.msu.edu/) were matched with those from NCBI

(which uses a different loci system). The identification of loci in NCBI was

performed by comparing the protein sequences in the Rice Genome

Annotation Project database to protein sequences in the NCBI database

using the BLASTP program. Other loci were identified using the

UniProtKB database (http://www.uniprot.org/help/uniprotkb) by searching

using the word "serpin" and then checking the identity of the hits based on amino-acid sequence.

\section{Abbreviations}

aa: Amino-acid residues; CP value: Crossing-point value (identical to $\mathrm{Ct}$ (crossing threshold) value); MS media: Murashige \& Skoog media; MudPIT: Multidimensional Protein Identification Technology; RCL: Reactive-Centre Loop.

\section{Competing interests}

The authors declare no competing interests.

\section{Authors' contributions}

BJA directed all aspects of growing the rice plants and assisted with data analysis. RAE designed and conducted the real-time RT-PCR experiments and replicates of the semi-quantitative RT-PCR experiments. THR and SEF designed the semi-quantitative RT-PCR and genomic PCR experiments and SEF conducted them. J-WA assisted in the design of all molecular biology aspects of the project. THR conducted the sequence and phylogenetic analyses with assistance from SEF. THR conceived the research, designed the new serpin nomenclature, assessed the data and wrote the manuscript with assistance from the other authors. All authors read and approved the final manuscript.

\section{Acknowledgements}

We thank Muhammad Masood for assistance in growing the rice plants, Suzanne Artiss for technical assistance and Jørn Hejgaard (Technical University of Denmark) for helpful discussions. Funding for this work was provided in the form of Macquarie University Research Scholarships (iMURS) to RAE and J-WA, Macquarie University Faculty of Science research funding allocations to RAE, SEF and J-WA and a Macquarie University Research and Development Grant (MQRDG) to THR.

\section{Author details}

${ }^{1}$ Department of Chemistry and Biomolecular Sciences, Macquarie University, North Ryde, NSW 2109, Australia. ²Department of Biological Sciences, Macquarie University, North Ryde, NSW 2109, Australia. ${ }^{3}$ Department of Plant and Food Sciences, Faculty of Agriculture and Environment, University of Sydney, Sydney, NSW 2006, Australia. ${ }^{4}$ Green Bio Research Center, Korea Research Institute of Bioscience and Biotechnology (KRIBB), 111 Gwahangno, Yuseong-gu, Daejeon 305-806, Korea. 
Received: 10 January 2012 Accepted: 19 March 2012

Published: 4 September 2012

\section{References}

1. Rawlings ND: Peptidase inhibitors in the MEROPS database. Biochimie 2010, 92:1463-1483.

2. Law RHP, Zhang QW, McGowan S, Buckle AM, Silverman GA, Wong W, Rosado CJ, Langendorf CG, Pike RN, Bird PI, et al: An overview of the serpin superfamily. Genome Biol 2006, 7:216

3. Silverman GA, Whisstock JC, Bottomley SP, Huntington JA, Kaiserman D, Luke CJ, Pak SC, Reichhart JM, Bird PI: Serpins flex their muscle: I. Putting the clamps on proteolysis in diverse biological systems. J Biol Chem 2010, 285:24299-24305.

4. Rau JC, Beaulieu LM, Huntington JA, Church FC: Serpins in thrombosis, hemostasis and fibrinolysis. J Thromb Haemost 2007, 5(Suppl 1):102-115.

5. Huber R, Carrell RW: Implications of the three-dimensional structure of alpha 1- antitrypsin for structure and function of serpins. Biochemistry 1989, 28:8951-8966.

6. Silverman GA, Bird Pl, Carrell RW, Church FC, Coughlin PB, Gettins PGW, Irving JA, Lomas DA, Luke CJ, Moyer RW, et al: The serpins are an expanding superfamily of structurally similar but functionally diverse proteins - Evolution, mechanism of inhibition, novel functions, and a revised nomenclature. J Biol Chem 2001, 276:33293-33296.

7. Lampl N, Budai-Hadrian O, Davydov O, Joss TV, Harrop SJ, Curmi PM, Roberts TH, Fluhr R: Arabidopsis AtSerpin1: crystal structure and in vivo interaction with its target protease responsive to desiccation-21 (RD21). J Biol Chem 2010, 285:13550-13560.

8. Whisstock JC, Silverman GA, Bird PI, Bottomley SP, Kaiserman D, Luke CJ, Pak SC, Reichhart JM, Huntington JA: Serpins flex their muscle: II. Structural insights into target peptidase recognition, polymerization, and transport functions. J Biol Chem 2010, 285:24307-24312.

9. Carrell RW, Evans DL, Stein PE: Mobile reactive centre of serpins and the control of thrombosis. Nature 1991, 353:576-578.

10. Schechter I, Berger A: On the size of the active site in proteases. I. Papain. Biochem Biophys Res Commun 1967, 27:157-162.

11. Lawrence DA, Ginsburg D, Day DE, Berkenpas MB, Verhamme IM, Kvassman JO, Shore JD: Serpin-protease complexes are trapped as stable acyl-enzyme intermediates. J Biol Chem 1995, 270:25309-25312.

12. Stratikos $E$, Gettins PG: Formation of the covalent serpin-proteinase complex involves translocation of the proteinase by more than $70 \AA$ and full insertion of the reactive center loop into beta-sheet A. Proc Natl Acad Sci USA 1999, 96:4808-4813

13. Huntington JA, Read RJ, Carrell RW: Structure of a serpin-protease complex shows inhibition by deformation. Nature 2000, 407:923-926.

14. Carrell RW, Owen MC: Plakalbumin, alpha 1-antitrypsin, antithrombin and the mechanism of inflammatory thrombosis. Nature 1985, 317:730-732.

15. Dementiev A, Dobo J, Gettins PG: Active site distortion is sufficient for proteinase inhibition by serpins: structure of the covalent complex of alpha1-proteinase inhibitor with porcine pancreatic elastase. J Biol Chem 2006, 281:3452-3457.

16. Chaillan-Huntington CE, Gettins PGW, Huntington JA, Patston PA: The P6-P2 region of serpins is critical for proteinase inhibition and complex stability. Biochemistry 1997, 36:9562-9570.

17. Plotnick MI, Schechter NM, Wang ZM, Liu X, Rubin H: Role of the P6-P3' region of the serpin reactive loop in the formation and breakdown of the inhibitory complex. Biochemistry 1997, 36:14601-14608.

18. Stein $P E$, Tewkesbury DA, Carrell RW: Ovalbumin and angiotensinogen lack serpin S-R conformational change. Biochem J 1989, 262:103-107.

19. Klieber MA, Underhill C, Hammond GL, Muller YA: Corticosteroid-binding globulin, a structural basis for steroid transport and proteinase-triggered release. J Biol Chem 2007, 282:29594-29603.

20. Zhou A, Wei Z, Read RJ, Carrell RW: Structural mechanism for the carriage and release of thyroxine in the blood. Proc Natl Acad Sci USA 2006, 103:13321-13326

21. Hejgaard J, Roberts TH: Plant Serpins. In Molecular and Cellular Aspects of the Serpinopathies and Disorders in Serpin Activity. Edited by Silverman GA, Lomas DA. New Jersey: World Scientific; 2007:279-300.

22. Roberts $\mathrm{TH}$, Hejgaard J: Serpins in plants and green algae. Funct Integr Genomics 2008, 8:1-27.
23. Fluhr R, Lampl N, Roberts $T H$ : Serpin protease inhibitors in plant biology Physiol Plant 145:95-102.

24. Fetterer RH, Miska KB, Jenkins M, Barfield R, Lillehoj H: Identification and characterization of a serpin from Eimeria acervulina. J Parasitol 2008:1269-1274.

25. Roberts TH, Hejgaard J, Saunders NFW, Cavicchioli R, Curmi PMG: Serpins in unicellular Eukarya, Archaea, and Bacteria: Sequence analysis and evolution. J Mol Evol 2004, 59:437-447.

26. Riahi Y, Siman-Tov R, Ankri S: Molecular cloning, expression and characterization of a serine proteinase inhibitor gene from Entamoeba histolytica. Mol Biochem Parasitol 2004, 133:153-162.

27. Irving JA, Cabrita LD, Rossjohn J, Pike RN, Bottomley SP, Whisstock JC: The 1.5 angstrom crystal structure of a prokaryote serpin: Controlling conformational change in a heated environment. Structure 2003, 11:387-397.

28. Irving JA, Steenbakkers PJM, Lesk AM, den Camp HJMO, Pike RN, Whisstock $J C$ : Serpins in prokaryotes. Mol Biol Evol 2002, 19:1881-1890.

29. Zhang Q, Law R, Buckle AM, Cabrita L, McGowan S, Irving JA, Faux NG, Lesk AM, Bottomley SP, Whisstock JC: Serpins in Prokaryotes. In Molecular and Cellular Aspects of the Serpinopathies and Disorders in Serpin Activity. Edited by Silverman GA, Lomas DA. New Jersey: World Scientific; 2007:131-162.

30. Dahl SW, Rasmussen SK, Hejgaard J: Heterologous expression of three plant serpins with distinct inhibitory specificities. J Biol Chem 1996, 271:25083-25088.

31. Dahl SW, Rasmussen SK, Petersen LC, Hejgaard J: Inhibition of coagulation factors by recombinant barley serpin BSZx. FEBS Lett 1996, 394:165-168.

32. Hejgaard J, Hauge S: Serpins of oat (Avena sativa) grain with distinct reactive centres and inhibitory specificity. Physiol Plant 2002, 116:155-163.

33. Hejgaard J, Laing WA, Marttila S, Gleave AP, Roberts TH: Serpins in fruit and vegetative tissues of apple (Malus domestica): expression of four serpins with distinct reactive centres and characterisation of a major inhibitory seed form, MdZ1b. Funct Plant Biol 2005, 32:517-527.

34. Ostergaard H, Rasmussen SK, Roberts TH, Hejgaard J: Inhibitory serpins from wheat grain with reactive centers resembling glutamine-rich repeats of prolamin storage proteins - Cloning and characterization of five major molecular forms. J Biol Chem 2000, 275:33272-33279.

35. Rasmussen SK, Dahl SW, Norgard A, Hejgaard J: A recombinant wheat serpin with inhibitory activity. Plant Mol Biol 1996, 30:673-677.

36. Yoo BC, Aoki K, Xiang Y, Campbell LR, Hull RJ, Xoconostle-Cazares B, Monzer J, Lee JY, Ullman DE, Lucas WJ: Characterization of Cucurbita maxima phloem serpin-1 (CmPS-1) - A developmentally regulated elastase inhibitor. J Biol Chem 2000, 275:35122-35128.

37. Vercammen D, Belenghi $B$, van de Cotte B, Beunens T, Gavigan JA, De Rycke R, Brackenier A, Inze D, Harris $J$, Van Breusegem F: Serpin1 of Arabidopsis thaliana is a suicide inhibitor for Metacaspase 9. J Mol Biol 2006, 364:625-636.

38. Wang Z, Gu C, Colby T, Shindo T, Balamurugan R, Waldmann H, Kaiser M, van der Hoorn RA: Beta-lactone probes identify a papain-like peptide ligase in Arabidopsis thaliana. Nat Chem Biol 2008, 4:557-563.

39. Ahn JW, Atwell BJ, Roberts TH: Serpin genes AtSRP2 and AtSRP3 are required for normal growth sensitivity to a DNA alkylating agent in Arabidopsis. BMC Plant Biol 2009, 9:52.

40. Chenna R, Sugawara H, Koike T, Lopez R, Gibson TJ, Higgins DG, Thompson JD: Multiple sequence alignment with the Clustal series of programs. Nucl Acids Res 2003, 31:3497-3500.

41. Zhou AW, Carrell RW, Huntington JA: The serpin inhibitory mechanism is critically dependent on the length of the reactive center loop. J Biol Chem 2001, 276:27541-27547.

42. Swofford DL: PAUP. Phylogenetic analysis using parsimony (and other methods). In. Version 4 edn: Sinauer and Associates, Sunderland, Massachusetts; 2002.

43. Page RD: Visualizing phylogenetic trees using TreeView. Curr Protoc Bioinform 2002, Chapter 6: Unit 62

44. Hejgaard J: Purification and properties of protein Z - a major albumin of barley endosperm. Physiol Plant 1982, 54:174-182.

45. Carrell R, Travis J: Alpha1-antitrypsin and the serpins: variation and countervariation. Trends Biochem Sci 1985, 10:20-24.

46. Yeu SY, Park BS, Sang WG, Choi YD, Kim MC, Song JT, Paek N-C, Koh H-J, Seo HS: The serine proteinase inhibitor OsSerpin is a potent tillering regulator in rice. J Plant Biol 2007, 50:600-604. 
47. Lesk AM: Introduction to Protein Architecture. Oxford: Oxford University Press; 2001.

48. Irving JA, Pike RN, Lesk AM, Whisstock JC: Phylogeny of the serpin superfamily. Implications of amino acid conservation for structure and function. Genome Res 2000, 10:1845-1864.

49. Giese H, Hejgaard J: Synthesis of salt-soluble proteins in barley. Pulse-labeling study of grain filling in liquid-cultured detached spikes. Planta 1984, 161:172-177.

50. Brandt A, Svendsen I, Hejgaard J: A plant serpin gene. Structure, organization and expression of the gene encoding barley protein Z4. Eur J Biochem 1990, 194:499-505.

51. Koller A, Washburn MP, Lange BM, Andon NL, Deciu C, Haynes PA, Hays L, Schieltz D, Ulaszek R, Wei J, et al: Proteomic survey of metabolic pathways in rice. Proc Natl Acad Sci USA 2002, 99:11969-11974.

52. Roberts TH, Marttila S, Rasmussen SK, Hejgaard J: Differential gene expression for suicide-substrate serine proteinase inhibitors (serpins) in vegetative and grain tissues of barley. J Exp Bot 2003, 54:2251-2263.

53. Chichkova NV, Shaw J, Galiullina RA, Drury GE, Tuzhikov Al, Kim SH, Kalkum $M$, Hong TB, Gorshkova EN, Torrance $L$, et al: Phytaspase, a relocalisable cell death promoting plant protease with caspase specificity. EMBO J 2010, 29:1149-1161

54. Hejgaard J: Inhibitory serpins from rye grain with glutamine as P-1 and $\mathrm{P}-2$ residues in the reactive center. FEBS Lett 2001, 488:149-153.

55. Hejgaard J: Inhibitory plant serpins with a sequence of three glutamine residues in the reactive center. Biol Chem 2005, 386:1319-1323.

56. Levashina EA, Langley E, Green C, Gubb D, Ashburner M, Hoffmann JA Reichhart JM: Constitutive activation of toll-mediated antifungal defense in serpin-deficient Drosophila. Science 1999, 285:1917-1919.

57. Gettins PGW: Serpin structure, mechanism, and function. Chem Rev 2002, 102:4751-4803.

58. Bajguz A, Hayat S: Effects of brassinosteroids on the plant responses to environmental stresses. Plant Physiol Biochem 2009, 47:1-8.

59. la Cour Petersen M, Hejgaard J, Thompson GA, Schulz A: Cucurbit phloem serpins are graft-transmissible and appear to be resistant to turnover in the sieve element-companion cell complex. J Exp Bot 2005, 56:3111-3120.

doi:10.1186/1471-2164-13-449

Cite this article as: Francis et al:: Serpins in rice: protein sequence analysis, phylogeny and gene expression during development. BMC Genomics 2012 13:449.

\section{Submit your next manuscript to BioMed Central and take full advantage of:}

- Convenient online submission

- Thorough peer review

- No space constraints or color figure charges

- Immediate publication on acceptance

- Inclusion in PubMed, CAS, Scopus and Google Scholar

- Research which is freely available for redistribution

Submit your manuscript at www.biomedcentral.com/submit
CioMed Central 